\title{
O PRINCÍPIO DA IGUALDADE E AS COTAS RACIAIS COMO INGRESSO NO ENSINO SUPERIOR: UMA QUESTÃO CONSTITUCIONAL
}

\author{
Evelyn Pereira da Silva, Ana Augusta Rodrigues Westin Ebaid \\ Universidade do Oeste Paulista - UNOESTE, Curso de Direito, Presidente Prudente, SP. E-mail: \\ evelyn1.pereira@hotmail.com
}

\begin{abstract}
RESUMO
O estudo buscou investigar as ações afirmativas, em primordial as cotas raciais com o objetivo de ponderar sua submissão a Constituição Federal. A evolução histórica fundamenta a discrepância social em relação aos grupos étnico-raciais, principalmente quando tratamos dos afrosdescendentes, o que dificultou a sua trajetória ao acesso educacional. A perquirição do tema buscou abranger um lado social e outro jurídico, demonstrando a desarmonia em relação aos pensadores da imprescindibilidade das políticas públicas voltadas ao mecanismo de acesso ao ensino superior. Através de pesquisa descritiva, mas caracterizada com método hipotético dedutivo, buscou-se dar maior abrangência ao princípio da igualdade, analisando adversidade em relação à efetivação do direito fundamental a educação, analisando as conjecturas e concluindo que a igualdade abrange aspectos formais e materiais, com espeque em uma natureza jurídica compensatória o que não importa em uma inconstitucionalidade.

Palavras-chave: Princípio da igualdade. Políticas públicas. Cotas raciais. Ação afirmativa. Ensino superior
\end{abstract}

THE PRINCIPLE OF EQUALITY AND RACIAL QUOTAS AS ENTRY IN HIGHER EDUCATION: A CONSTITUTIONAL ISSUE

\begin{abstract}
The study sought to investigate the affirmative actions, in primordial racial quotas with the objective of pondering their submission to the Federal Constitution. Historical evolution is based on the social discrepancy in relation to ethnic-racial groups, especially when dealing with Afrodescendants, which hindered their trajectory to educational access. The examination of the theme sought to cover a social and a legal side, demonstrating the disharmony in relation to the thinkers of the indispensability of the public policies focused on the mechanism of access to higher education. Through a descriptive research, but characterized by a deductive hypothetical method, it was sought to give greater scope to the principle of equality, analyzing adversity in relation to the effectiveness of the fundamental right to education, analyzing the conjectures and concluding that equality encompasses formal and material aspects, with in a compensatory legal nature that does not matter in an unconstitutionality.
\end{abstract}

Keywords: Principle of Equality .Public policies. Racial quotas. Affirmative Action . higher education 


\section{INTRODUÇÃO}

As cotas raciais são à base das políticas públicas nas universidades, isto dado o contexto histórico escravista e a enorme quantidade de afrosdescendentes. $O$ fato é que o país instituiu a natureza jurídica compensatória, buscando a longo e médio prazo o acesso à educação a população esmiuçada nos aspectos proposto pelo projeto.

A Constituição da Republica Federativa do Brasil em seu artigo 3o, inciso IV, deliberou como objetivo promover o bem de todos sem descriminações. Em seu artigo 50 "caput", consagrou o princípio da igualdade e em mesmo artigo, inciso XLII consagrou o repúdio ao racismo, ou seja, o legislador buscou nestes dispositivos dar importância a não discriminação e repúdio a qualquer diferenciação de raça.

Para tanto, a exposição do tema tem por objetivo o estudo das políticas afirmativas, sua compatibilidade com o princípio da igualdade, seus limites, eficácia frente à discrepância de opiniões e sua constitucionalidade.

\section{METODOLOGIA}

O presente trabalho foi desenvolvido pela coleta de jurisprudências, verificando as tendências dos tribunais, bem como pela interpretação das discussões e posições doutrinárias.

De cunho conceitual e reflexivo, foi desenvolvido amplamente pelas perspectivas jurídicas, com características qualitativas, analisando e interpretando os pareceres dos julgados.

Trata-se, portando, de artigo com método hipotético dedutivo, partindo de uma regra geral, estabelecida em lei e em textos jurídicos, para a delimitação de um objeto especifico.

\section{DISCUSSÃO}

A Constituição Federal de 1988 é um marco histórico em relação a igualdade, com sua promulgação reconheceu-se a necessidade de igualdade e sustentou-se a necessidade de promoção de metas para valorizar diferentes grupos sociais.

O legislador atentou-se a localização normativa do artigo 5o da Constituição, foi uma demonstração de sua real importância e compromisso com as garantias fundamentais.

Os dispositivos constitucionais não só consagram o princípio da igualdade como também busca promovê-lo. $\mathrm{O}$ artigo 30 da Carta Magna traz como objetivo, a redução da desigualdade social e regional e no inciso IV a promoção do bem de todos, sem preconceito de origem, raça, sexo, cor, idade e qualquer outra forma de discriminação.

Por ser uma Constituição social permite uma ação governamental mais flexível, buscando reduzir desigualdades sociais, em um espaço de diversidades. Para tanto a igualdade na norma descrita, é perante a lei e na lei.

A doutrina distingue o princípio da igualdade em dois aspectos - formal e material o primeiro, é uma igualdade perante a própria norma, ou seja, a lei dirige-se a todos sem distinções, já quanto ao segundo, têm-se o entendimento que a lei deve ser efetivada observando-se a igualdade formal e se dirige a seus interpretes.

Acerca desta distinção discorre Junior (2008, p. 636):

O direito à igualdade é o direito que todos têm de ser tratados igualmente na medida em que se igualem e desigualmente na medida em que se desigualem, quer perante a ordem jurídica (igualdade formal), quer perante a oportunidade de acesso aos bens da vida (igualdade material), pois todasas pessoas nascem livres e iguais em dignidade e direitos. 
Ou seja, o aspecto formal se dirige ao legislador e o aspecto material aos seus destinatários.

Ainda, buscando efetivar esta igualdade, mas com fim de atingir seu aspecto material, tratou o legislador no artigo 4ㅇ da Carta magna, do repudio ao racismo, visando repelir as ações discriminatórias, garantindo assim os direitos huma

Leciona doutrinador José Afonso da Silva (2014, p. 216):

$\mathrm{O}$ texto constitucional, que proíbe preconceito de origem, cor, e raça e condena discriminações com base nesses fatores, consubstancia, antes de tudo, o reconhecimento de que o preconceito de origem, raça e cor especialmente contra os negros não está ausente das relações sociais brasileiras. Disfarçadamente ou, não raro, ostensivamente, pessoas negras sofrem discriminação até mesmo nas relações com entidades públicas.

Em outros artigos e não só nestes mencionados fez por bem o legislador por relembrar a aplicação do princípio da igualdade, principalmente em relação à discriminação, sendo um espeque para as chamadas ações afirmativas.

As ações afirmativas são medidas governamentais que buscam reverter o quadro de desigualdade de algumas minorias, promovendo a oportunidade no mercado de trabalho e na educação.

Segundo Jaccoud e Beghin (2002, p. 56), as ações afirmativas são aquelas que:

Têm por objetivo garantir a oportunidade de acesso dos grupos discriminados, ampliando sua participação em diferentes setores da vida econômica, política, institucional, cultural e social. Elas se caracterizam por serem temporárias e por serem focalizadas no grupo discriminado, ou seja, por dispensarem, num determinado prazo, um tratamento diferenciado e favorável com vistas a reverter um quadro histórico de descriminação e exclusão.

No mesmo contexto, as ações ou políticas afirmativas são critérios que buscam o desenvolvimento social e a redução das desigualdades raciais. Busca-se dar diversidade aos grupos elitizados e igualdade de oportunidades entre as classes.

Para que grupos discriminados tenham igualdade de oportunidades, necessários são os mecanismos educacionais, o ingresso de negros tanto na educação pública e privada.

Na mesma lógica expõe Oliveira et al. (2007), que deve haver uma mobilização por meio do Estado, buscando estratégias que organizem as políticas públicas, principalmente no campo educacional, o ingresso de negros na educação superior.

Estas políticas são descriminações positivas que fornecem privilégios para grupos específicos buscando uma igualdade.

A fim de trazer equidade, e diminuir esta descriminação racial o governo elaborou ações para reparar as desigualdades advindas do escravismo. Assim, foram criadas as chamadas políticas afirmativas.

Assim explica Sell (2002, p.15):

A Ação Afirmativa consiste numa série de medidas destinadas a corrigir uma forma específica de desigualdade de oportunidades sociais: aquela que parece estar associada a determinadas características biológicas (comoraça e sexo) ou sociológicas (como etnia e religião), que marcam a identidade de certos grupos na sociedade.

Como espécies destas políticas afirmativas foram criadas as cotas raciais, estas estão presentes nas faculdades e universidades, são assim discriminações positivas, pois não singularizam um determinado sujeito, mas criam parâmetros para resguardar os direitos 
daqueles que nesta condição estiverem.

Como em outros países, no Brasil o sistema de cotas foi implantado nos anos 2000, garantindo $50 \%$ das vagas para estudantes das escolas públicas, e mais tarde, no ano de 2001, institui-se para pardos e negros.

Problemas ocorrem, quando parcela de pensadores entendem que o sistema de cotas apenas agrava as desigualdades.

Argumentos contrários ao sistema de cotas reforçam que esta política vai contra ao estabelecido no artigo 5o da Constituição Federal de 1988, pois o tratamento diferenciado ofende o princípio da igualdade, assim, seria uma hipocrisia a interpretação de garantias aos negros.

Neste espeque aponta os autores Feres e Neto (2010, p.348):

Há uma quantidade imensa de equívocos e inexatidões históricas e lógicas nesse raciocínio. Em primeiro lugar, ele parte do pressuposto histórico falso de que a escravidão foi um fato racial, em que uma raça (a branca) teria escravizado outra raça (a negra). Na verdade, a escravidão foi um fato econômico que não seria possível sem que reais interesses comerciais relacionados ao tráfico transatlântico existissem em ambas as margens do oceano

Ou seja, entendem que a discriminação histórica, não era uma questão de raça ou etnia e sim, uma questão econômica. Pelo qual, negros que detinham força econômica poderiam dominar brancos e outros negros, não havendo pressuposto para as cotas raciais

Os opositores do sistema de cotas são seguidores do universalismo meritocrático, eles alegam que o mérito individual estaria negado, sendo necessário cada candidato realizar o vestibular com a mesma oportunidade, elevando o mérito individual de cada candidato, não oportunizando desvantagens para obter igualdade.

"Antes de tudo, a meritocracia é uma ideologia que esconde a produção social do conhecimento e a hierarquia dos saberes acadêmicos legitimada previamente à conclusão entres os candidatos do exame." (CARVALHO, 2011, p. 189)

Estas controvérsias acerca da política surgiram como causa de resistência e com o fim de inibir as universidades de aderir às ações afirmativas.

Neste espeque em 2009 o partido Democrata ajuizou uma ação de descumprimento de um preceito fundamental que questionou a aplicação do sistema de cotas na Universidade de Brasília (UnB) e sua inconstitucionalidade diante dos artigos 10, caput, III, 3으, IV, 4ㅇ, VIII, 5ㅇ, I, II XXXIII, XLI, LIV, 37, caput, 205, 206, caput, I, 207, caput, e 208, inciso V, todos da Constituição Federal.

O requerente alegou na Argüição de Preceito Fundamental que as medidas tomadas não são factíveis, visto que, a Teoria da Justiça Compensatória não pode comprometer a geração presente pelos indivíduos do passa.

Além disse apontaram que os dados estáticos sofreram manipulações, asseverando que os pardos eram incluídos como negros, para demonstrar que a metade da população vive excluída das universidades.

Em objeção, a UnB alegou que a implementação de cotas raciais é ainda insuficiente para alcançar a igualdade e que apenas a lei que estipulou o fim do racismo não foi suficiente para velá-lo.

Afirmaram, ainda, que o sistema de reservas de vagas é temporário e se findará quando forem eliminadas as restrições de acesso as categorias marginalizadas.

Logo, o objetivo do legislador ao elaborar políticas publicas que fossem passiveis de aplicação material, foi garantir o desenvolvimento da sociedade, isto vai além de dar 
benefícios aos avantajados economicamente, visa garantir a padrões de qualidade e o ensino democratizado.

O fato de o Brasil garantir oportunidades aos negros e pardos que sejam de baixa renda, concede o maior desenvolvimento ao país em todas as áreas, o aumento da escolaridade interfere em outros índices relevantes como a economia, cidadania e saúde.

O legislador da Constituição de 1988 em seu artigo 205 consagra a educação como um direito de todos e um dever do Estado e ainda no artigo 206 garantiu a oportunidade de condições.

Com a "Lei de Diretrizes e Bases" foi possível a universalização do acesso ao nível superior, e mais tarde com o advento da lei que consagrou as cotas raciais, as universidades puderam gozar de autonomia para dispor de vagas. A observância deve estar sobre as diretrizes do conselho nacional de educação que exige a conclusão do ensino médio e a aprovação do processo seletivo e em relação às cotas critério étnico-racial e econômico.

De acordo com Pacheco e Silva (2007, p. 8), "os países do mundo hoje considerados como os mais desenvolvidos são aqueles que investiram e investem maciçamente na educação."

A educação é direito fundamental de segunda geração, desta forma o Estado deve agir para que este esteja consagrado e tenha efeitos materiais.

Dada a controvérsia em abril de 2012 decidiu o Supremo Tribunal Federal pela constitucionalidade das cotas raciais nas Universidades públicas.

O Supremo, por meio do acórdão decidiu que as cotas visam eliminar todas as restrições de acesso aos grupos marginalizados e que deveria permanecer até que houvesse a democratização do acesso à Universidade, tomando por improcedente a ADPF.

Os ministros fundamentaram o acórdão alegando que cada universidade goza de sua autonomia didática, o que implica no poder de decidir em buscar políticas públicas para reduzir as desigualdades sócias, dado o papel integrador da educação, bem como ter as cotas raciais natureza jurídica meramente compensatória, descrevendo que no Brasil, justamente por conta da historicidade da escravidão e das dificuldades enfrentadas pelos afro-brasileiros após a assinatura da Lei Áurea, buscou-se enfatizar os sistemas de cotas e os estatutos que buscam a igualdade racial, logo de natureza compensatória têm como objetivo o ressarcimento das atrocidades cometidas historicamente.

Ademais, respaldaram que o princípio da igualdade é mandamento nuclear do artigo quinto da Constituição federal e que suas disposições acabam por irradiar em diversos âmbitos sociais e do ponto de vista material é superior as normas, por isso deve ser seguido substancialmente.

A Constituição de 1988 é a que instituiu um Estado democrático de direito, fundado na cidadania e com objetivo de uma sociedade livre, justa e solidária.

Através dos dados estáticos em praticamente todos os indicadores sociais observa-se a disparidade entre raças. Tudo isso leva a crer que é necessária a democratização em diversas áreas.

A proposta das cotas, jamais previu uma política por prazo indeterminado. O sistema adotado visa mera temporalidade, e tem o condão de compensar as experiências negativas deixadas pela história, não se estendendo demasiadamente, tendo o modelo especifico de caráter temporário.

Ou seja, a partir das transformações latentes na realidade social, com a erradicação da desigualdade a ação afirmativa seja de cunho racial, ou outro aspecto devem se findar, pois já atingiram seus objetivos. 
Ainda as metas não foram atingidas, com uma população de negros que chega ao percentual de $47 \%$, segundo o IBGE, apenas $10 \%$ de estudantes negros e pardos freqüentam faculdade e universidades e $1 \%$ trabalha como docentes (CARVALHO, 2011).

O negro ao tentar ingressar nas faculdades ou universidades enfrenta um duplo obstáculo, questões históricas e econômicas. A compensação ofertada visa reparar os dados históricos e a vulnerabilidade que este grupo encontra.

$\mathrm{O}$ acesso destes afrodescendentes ao ensino superior é ainda pequeno, as outorgas destas políticas nada mais são que temporárias e razoáveis a fim de garantir o preceito constitucional de igualdade.

A admissão deste grupo tem inúmeros objetivos, a concretização de maiores oportunidades, alterações sociais, pedagógicas e culturais, aumento da representatividade dos grupos menos favorecidos, entre outros. (SISS, 2003).

Em nosso diploma jurídico temos algumas leis que amparam estas políticas. A lei $10.558 / 2002$, conhecida como a "Lei de cotas" apresenta a política de ingresso, chamada programa diversidade na universidade, e a lei 12.288/2010 que é conhecida como o "Estatuto da Igualdade Racial", e em 2012 foi instituída a Lei 12.771/12, também conhecida como Programa de Universidade para Todos, que estipula que $50 \%$ das vagas serão destinadas a negros nos processos seletivos de universidades.

A aplicação de cotas nas faculdades e universidades guarda relevância em quatro pilares, o primeiro de uma reparação histórica, advinda da escravidão, um segundo da aplicação de um direito consagrado na Constituição, em relevância o princípio da igualdade, um terceiro em avanço acadêmico, baseado em enriquecimento social, e, por fim, luta contra a discriminação racial, buscando igualdade na realidade social.

Em suma, os incentivos que visam erradicar as desigualdades, e desde seu surgimento já apresentam cunho temporário, não serão irresolutos, bem como imprescindíveis buscando a igualdade material.

\section{CONCLUSÃO}

A implementação de cotas é uma espécie das políticas públicas voltadas a oferecer oportunidade de condições aos grupos marginalizados.

A Constituição Federal de 1988 é um marco, também conhecida como a constituição cidadã, que consagrou o princípio da igualdade, no qual abrange seu cunho material e a formal.

As ações afirmativas, dentre elas as cotas, apresenta cunho material, buscando efetivar o princípio descrito no artigo 5으 da Constituição Federal. É notória a desigualdade vivida com discrepância em relação à raça.

Assim, entende-se que as cotas são medidas constitucionais, e são efetivações dos artigos 60 e 205 da Constituição Federal de 1988, o direito a educação é um direito de todos e dever do Estado, que o dispôs como direito fundamental de segunda geração.

A conclusão que se faz é que o ensino superior é um direito fundamental, positivado na constituição, pautado no direito ao ensino e dever da formulação de políticas pelo Estado.

As cotas raciais instituem um direito social extremamente ligado a igualdade, a intervenção crescente tem trazido resultados, contudo é relevante a sua temporalidade e imprescindibilidade.

A perspectiva vai muito além de cegamente segregar a discriminação racial, torna-se um objetivo em tornar igual a competição, o rendimento, a trajetória, representa dar 
continuidade a uma igualdade puramente formal.

\section{REFERÊNCIAS}

BRASIL. Constituição (1988). Constituição da República Federativa do Brasil. Brasília: Senado Federal, 1988.

CARVALHO J. Inclusão étnica e racial no Brasil. 2 ed. São Paulo: Attar Editoral, 2011.

FERES, J.; NETO, S. Ação afirmativa: Normatividade e Constitucionalidade. 2 ed. Rio de Janeiro: Lumen Juris, 2010.

PACHECO, J.; SILVA, N. O negro na universidade: o direito a inclusão. 1. ed. Brasília: Fundação cultural Palmares, 2007. Disponível em:

<http://www.redeacaoafirmativa.ceao.ufba.br/uploads/palmares_livro_2007_JQPacheco_MN daSilva.pdf>. Acesso em: 28 mar. 2017.

IBGE. Instituto Brasileiro de Geografia e Estatística. População: Síntese de indicadores sociais $2010 . \quad$ Disponível em: <https://ww2.ibge.gov.br/home/estatistica/populacao/condicaodevida/indicadoresminimos /suppme/default_educacao.shtm>. Acesso em: 06 jan. 2018.

INEP. Instituto Nacional de Estudos e Pesquisa Educacionais Anísio Teixeira: Sinopses Estatísticas da Educação Superior 2016. Disponível em: <http http://sistemascensosuperior.inep.gov.br/censosuperior_2017/>. Acesso em: 06 jan. 2018

INEP. Instituto Nacional de Estudos e Pesquisa Educacionais Anísio Teixeira: Sinopses Estatísticas da Educação Superior 2010. Disponível em:

<http://portal.inep.gov.br/web/guest/sinopses-estatisticas-da-educacao-superior >. Acesso em: 06 jan. 2018

JACCOUD, L.; BEGHIN N. Desigualdades Raciais no Brasil. 1. ed. Brasília: Ipea, 2002.

OLIVEIRA, I. et al. Negro na educação 4. 1. ed. São Paulo: Anped, 2007.

SILVA, J. Curso de direito constitucional positivo. 97 ed. São Paulo: Malheiros, 2014. 
SISS, A. Afro-brasileiros, Cotas e Ação Afirmativa: Razões Históricas. 1. ed. Rio de Janeiro: Quartet-penesb-uff, 2003.

STF. STF julga constitucional política de cotas na Unb. Disponível em: <http://www.stf.jus.br/portal/cms/verNoticiaDetalhe.asp?idConteudo>. Acesso em: 10 nov. 2017. 